\title{
Unreliability Effects in Public Transport Modelling
}

\author{
Dr. ir. Niels van Oort ${ }^{1}$, Ir. Ties Brands ${ }^{2}$, Prof.dr. ir. Erik de Romph ${ }^{3}$, and Jessica \\ Aceves Flores, B. Eng. ${ }^{4}$ \\ ${ }^{1}$ Delft University of Technology / Goudappel Coffeng \\ ${ }^{2}$ University of Twente / Goudappel Coffeng \\ ${ }^{3}$ Delft University of Technology / DAT.Mobility \\ ${ }^{4}$ Delft University of Technology \\ ${ }^{1} N . v a n O o r t @ T U D e l f t . n l,{ }^{2}$ tbrands@goudappel.nl, ${ }^{3}$ ederomph@DAT.nl, \\ ${ }^{4}$ J.L.AcevesFlores@student.TUDelft.nl
}

\begin{abstract}
Nowadays, transport demand models do not explicitly evaluate the impacts of service reliability of transit. Service reliability of transit systems is adversely experienced by users, as it causes additional travel time and unsecure arrival times. Because of this, travellers are likely to perceive a higher utility from more reliable transport systems. In order to mimic and measure the impacts of service reliability on a transit demand model a three-step approach is proposed using automated vehicle location and smart card data. The approach consists of determining the probabilistic distribution of transit trip times, defining demand patterns and estimating the average impacts of unreliability per passenger. This approach was successfully tested on the model of the city of Utrecht in The Netherlands. By adding service reliability as a variable parameter of transit systems the results of the demand model improved, showing that the absolute difference between the observed and the estimated demand decreased by 18\%. In addition, the proposed approach allows measuring the effects of expected changes in level of service reliability on traveller behaviour. Finally, we identify future research topics required to improve the estimation of those effects.
\end{abstract}

Keywords: Reliability, public transport assignment, public transport modelling

\section{Introduction}

Service reliability has been researched for a long time for both car traffic and transit, studying its cause and measuring the magnitude of its consequences. The consequences of unreliability have been statistically analyzed in terms of probability of occurrence and related impacts on operations and infrastructure performance. It is still not common practice, however, to include service reliability as an explanatory variable in transport demand models in order to measure its impacts on the demand component of the transport network [1].

Public transport services have proven to represent sustainable transport solutions for mobility. Attention for studies related to public transport quality and efficiency is growing for its potential to increase its cost-effectiveness in order to prove financial feasibility. In particular service reliability has been pointed out as a recommended direction to improve transport models [2] showing statistical significance to explain passenger behaviour [3]. As a consequence nowadays several public transport projects aim at improving service reliability.

Public transport service reliability is the certainty with which service aspects (such as travel time, departure time and arrival time) match the scheduled aspects as perceived by 
the user $[4,5]$. Both passengers and operators benefit from enhanced service reliability by predictable travel times and by lower costs respectively.

Due to the lack of a proper theoretical framework that enables evaluating and predicting passenger impacts in a network context, commonly service reliability is not taken into account in transport demand models nor in most cost benefit analyses [6]. To our knowledge currently transport demand models assume that public transport is $100 \%$ punctual and the impacts of unreliability are only implicitly incorporated. This limits the prediction accuracy of the models and in addition it is not possible to estimate the impacts of expected changes of service reliability on transport demand and as a consequence on (societal) costs and benefits [6].

Developments and improvements of data availability in public transport, such as automated vehicle location (AVL) and automated passenger counting systems (APC), enable detailed research in order to develop measures to improve service reliability at all levels of public transport planning and operations as shown in [4, 7-13].

In this paper, a methodology is presented to integrate the estimation of the effects of service reliability on a static public transport demand model. This project is a first step to harmonize standards in demand modelling concerning public transport service reliability effects. The paper is organized as follows: the next section presents the state of the art of the impact of service reliability in discrete choice modelling. Section 3 provides the proposed approach developed to incorporate the effect of public transport service reliability in a transport demand model. In Section 4 the methodology is applied to a case study in the city of Utrecht, The Netherlands. Section 5 provides a discussion of the results and future research and finally conclusions are presented in Section 6.

\section{State of the Art of Modelling Service Reliability}

The level of service reliability affects several choices made by travellers, such as mode, route and departure time. In literature, much research is available with regard to passenger choices as a function of service reliability. According to [14] and [15] service reliability of public transport systems is considered critically important by most public transport users because passengers are adversely affected by the consequences associated with unreliability such as additional waiting time, late or early arrival at destinations and missed connections, generating a disutility associated to the transport alternatives in question.

There are two main approaches to model the effects of service reliability known as the mean-variance approach and the scheduling approach [3].

The mean-variance approach represents the effects of service reliability on mode and route choice as a function of the mean travel time, additional travel time and variance of travel time caused by unreliability, while the scheduling approach studies the impact of service reliability on the departure time choice as a function of the probability of early or late schedule adherence.

The scheduling approach originates from the theory that travellers experience a disutility from the consequences of travel time variability, namely arriving at the destination before or after the scheduled arrival time. It was initially proposed by Small [16]. It takes into account the experienced disutility of arriving early or late at the destination. There is a penalty of arriving late irrespective of how much.

The mean-variance approach, also known as the centrality-dispersion approach, originates from the theory that travellers place a disutility on travel time variability, and the uncertainty that comes with it. It was first proposed by [17] and extended by [18] to account for the distribution of the travel times. This approach assumes that the traveller makes a trade-off between expected travel time and variability of travel times. Different measures exist for travel time variability, however the standard deviation is mostly used ([19]). 
To our knowledge there is no generalized theoretical preference for one of these two approaches. Hollander [3] found that the likelihood of both estimated models were almost equal. A scheduling approach requires a dynamic model, where a static model is sufficient for implementing a mean variance approach. Thus, in order to implement service reliability in four step models the mean-variance approach is suggested [20]. The meanvariance approach consists on adding attributes of service reliability to the public transport generalized cost function along with other public transport attributes such as distance, travel time, waiting time, fare, and number of transfers.

For this research the destination and mode choice are modelled simultaneously through a gravity model using a deterrence function proportional to the generalized cost function. To model the variation in preference for route choice the Zenith method for public transport assignment as described in [21] is used with a logit formulation dependent on the generalized cost function including service reliability attributes.

The following section provides an explanation of the attributes of service reliability to include in the public transport generalized cost function in order to explain passenger behaviour in a transport demand model.

\section{Service Reliability Impacts on Passengers}

Unreliability causes longer and uncertain passenger journeys [4]. Figure 1 shows the passenger trip chain and its relation to vehicle processes. Public transport vehicles are scheduled to leave a stop at a departure time with a time interval from its predecessor known as headway. The successive part of the trip is the in-vehicle time. In this phase, the passenger time aspects are similar to those of the vehicle. If a passenger makes a transfer, a new waiting time for the passenger will arise. This new waiting time is affected by the planned synchronization between the two connecting vehicles, the actual performance of this synchronization and the waiting regime of the connecting vehicle [22].

The magnitude of the delays caused on the passenger waiting time by the adherence to the schedule depends on the passenger arrival pattern. If passengers arrive randomly, the headway between successive vehicles determines the waiting time [23]. If passengers arrive in conformance with the scheduled departure time, the deviation of the schedule adherence affects the waiting time [7]. For example if the vehicle departs earlier than scheduled, passengers have to wait a full headway.

Due to the stochastic nature, the impacts on individual passengers vary, however in an aggregated way passengers mainly experience the following three effects [18, 24 and 25]:

i. Impacts on duration of travel time components, being in-vehicle time and waiting time, which lead to arriving early or late;

ii. Impacts on passenger perception of the public transport mode depending on the variability of travel time components, being departure time, arrival time, in-vehicle time and waiting time, which lead to uncertainty of the actual travel time;

iii. Impact on the probability of finding a seat and of crowding, affecting the level of comfort of the journey. 


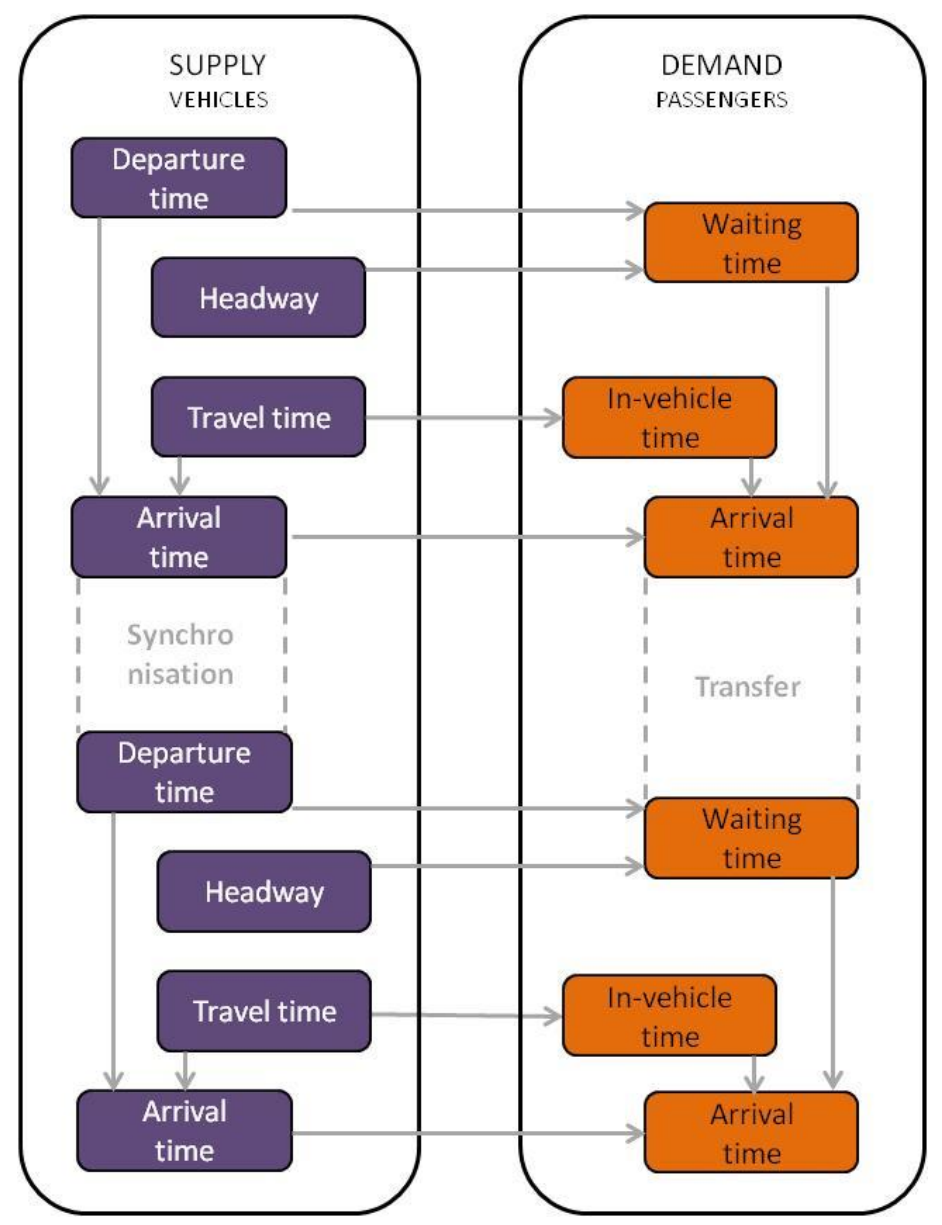

\section{Figure 1. Interaction of Passenger Trip Chain (Right) and Vehicle Characteristics (Left)}

This paper focuses on the first two aspects, namely the travel time related aspects. More detailed research on crowding may be found for instance in [26].

Actual departure times per stop, actual dwell times, actual headways and actual trip times are available from AVL systems or forecast tools such as illustrated in [27]. To calculate the passenger effects of unreliability this data is translated to passenger effects using APC data.

In an aggregated way, service reliability leads to an extension of passenger average travel time, since average waiting time per passenger may be extended due to irregular, early or late vehicles. To express the effect of service reliability on passengers an indicator called average additional travel time per passenger is introduced [28]. The second effect of service variability is the variance of passenger travel time.

Figure 2 illustrates the average additional travel time per passenger $\left(\mathrm{T}^{\mathrm{add}}\right)$ and the variability of actual travel time relative to the scheduled travel time [4]. It is important to note that $\mathrm{T}^{\mathrm{journey}}$, sched consists of the scheduled waiting time and the scheduled in-vehicle time. The latter is directly related to the scheduled vehicle trip time and is thus controllable being a function of schedule design (e.g., tight or loose schedule). Figure 2 shows that the additional travel time is distributed, due to variability of the operations. In some cases individual passengers may even arrive earlier than scheduled, when waiting and or in-vehicle time is shorter than planned. 


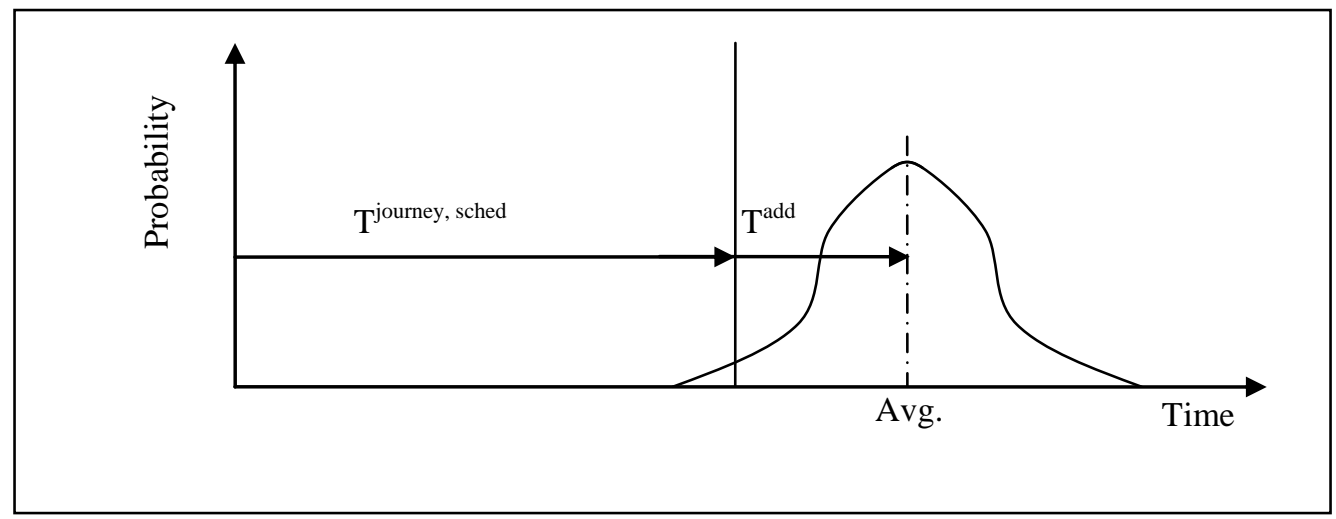

Figure 2. Scheduled Passenger Time ( $T^{\text {journey, sched }}$ ), Average Additional Travel Time per Passenger $\left(T^{\text {add }}\right)$ and Variance

Table 1 shows a matrix of four components that represent the passenger impacts of service reliability [4]. However, if operations are not controlled in any way (e.g., by holding vehicles), no additional in-vehicle trip time arises (compared to the average trip), so only the three remaining components shown in the matrix with the numbers 1,2 and 3 are investigated.

Table 1. Passenger Impacts of Service Reliability

\begin{tabular}{|c|c|c|}
\hline & Additional travel time & Travel time variance \\
\hline In-vehicle time & $n a$ & 2 \\
\hline Waiting time & 1 & 3 \\
\hline
\end{tabular}

Finally the passenger impacts of service reliability are represented by three attributes that are added to the generalized cost function: additional waiting time, in-vehicle travel time variance and waiting time variance. The proposed generalized cost function is shown in Equation 1.

$$
G C=\alpha+\beta_{1} d+\beta_{2}\left(\hat{T}+\hat{W}+\frac{\beta_{3}}{\beta_{2}} v\right)+\beta_{4} f+\beta_{5} N
$$

Where:

$$
\begin{array}{ll}
G C & =\text { generalized cost in } € \\
d & =\text { distance in } K m \\
\hat{T} & =\text { average travel time in hours } \\
\hat{W} & =W+T^{\text {add }} ; \text { average waiting time in hours } \\
v & =v_{\text {in - vehicle }}+v_{\text {waiting }} ; \text { variance of both in-vehicle and waiting time in hours } \\
f & =\text { fare in } € \\
N & =\text { number of transfers } \\
\alpha & =\text { alternative specific constant in } € \\
\beta_{1} & =\text { Coefficient of distance in } € / \text { Km } \\
\beta_{2} & =\text { Coefficient of travel time a.k.a. value of time in } € / \text { hour }
\end{array}
$$




$$
\begin{aligned}
& \beta_{3}=\text { Coefficient of variance of travel time a.k.a. value of reliability in } € / \text { hour } \\
& \frac{\beta_{3}}{\beta_{2}}=\text { reliability ratio } \\
& \beta_{4}=\text { Coefficient of public transport fares } \\
& \beta_{5}=\text { Coefficient of the number of transfers in } € / \text { transfer }
\end{aligned}
$$

In order to calculate the additional waiting time component, two situations have to be distinguished: high frequency public transport systems (with random arrivals of passengers at the stop) and low frequency public transport systems (with planned arrivals of passengers at the stop).

If passengers arrive randomly, exact departure times and punctuality are not relevant anymore, because passengers do not use a schedule. In that scenario, the additional travel time is calculated using the coefficient of variation $(\mathrm{CoV})$ of the actual headways $\left(\tilde{H}_{l, j}^{a c t}\right)$. A generic formulation to estimate the expected waiting time per passenger is given by Equation 2 [23, 29 and 30], according to the following assumptions:

- The examined period is homogeneous concerning scheduled departure times, trip times and headways (for instance rush-hour on working days in a month);

- All passengers are able to board to the first arriving vehicle.

$$
E\left(\tilde{T}_{l, j}^{\text {waiting }}\right)=\frac{E\left(\tilde{H}_{l, j}^{\text {act }}\right)}{2} *\left(1+\operatorname{CoV}^{2}\left(\tilde{H}_{l, j}^{\text {act }}\right)\right)
$$

Where:

$$
\begin{array}{ll}
\tilde{T}_{l, j}^{\text {waiting }} & =\text { passenger waiting time for line } l \text { at stop } j \\
\tilde{H}_{l, j}^{\text {act }} & =\text { actual headway of line } l \text { at stop } j \\
\operatorname{CoV}\left(\tilde{H}_{l, j}^{a c t}\right) & =\text { coefficient of variation of actual headways of line } l \text { at stop } j
\end{array}
$$

If the service is regular, the coefficient of variation equals zero and the average waiting time will be equal to half the headway. In the case of irregular service, the additional waiting time may then be calculated using Equation 3. Assuming no change in the actual vehicle trip times, the total average additional travel time per passenger will be equal to the average additional waiting time per passenger.

$$
E\left(\tilde{T}_{l, j}^{\text {Add waiting }}\right)=\frac{E\left(\tilde{H}_{l, j}^{a c t}\right)}{2} *\left(\operatorname{CoV}^{2}\left(\tilde{H}_{l, j}^{a c t}\right)\right)
$$

Where: $\quad E\left(\tilde{T}_{l, j}^{\text {Add, waiting }}\right)=$ average additional waiting time per passenger due to unreliability of line $l$ at stop $j$

For low frequency services it is known that passengers plan their arrival at the first stop of their trip according to the schedule and therefore another method of calculating additional travel time is necessary. Equations 4 and 5 show this method [7]. Passengers are assumed to arrive randomly within a range of the scheduled departure time minus $\tau_{\text {early }}$ and plus $\tau_{\text {late }}$ and if the vehicle departs within this time window it is assumed that passengers do not experience any additional waiting time. Figure 3 illustrate results of a 
passenger survey concerning the values of $\tau_{\text {early }}$ and $\tau_{\text {late }}$ [4]. It shows how early passengers arrive at the stop by showing the proportion of passengers arriving a certain amount of minutes before scheduled departure. In this case, they knew or checked the schedule before going to the stop. It appears that about $70 \%$ arrive within 2 minutes before the scheduled departure time. For our analysis, we propose to use a value of 2 minutes for $\tau_{\text {early }}$. This value represents the distribution of the arrival pattern of all passengers (consisting of arrival times of more and less than 2 minutes early) in a proper way.

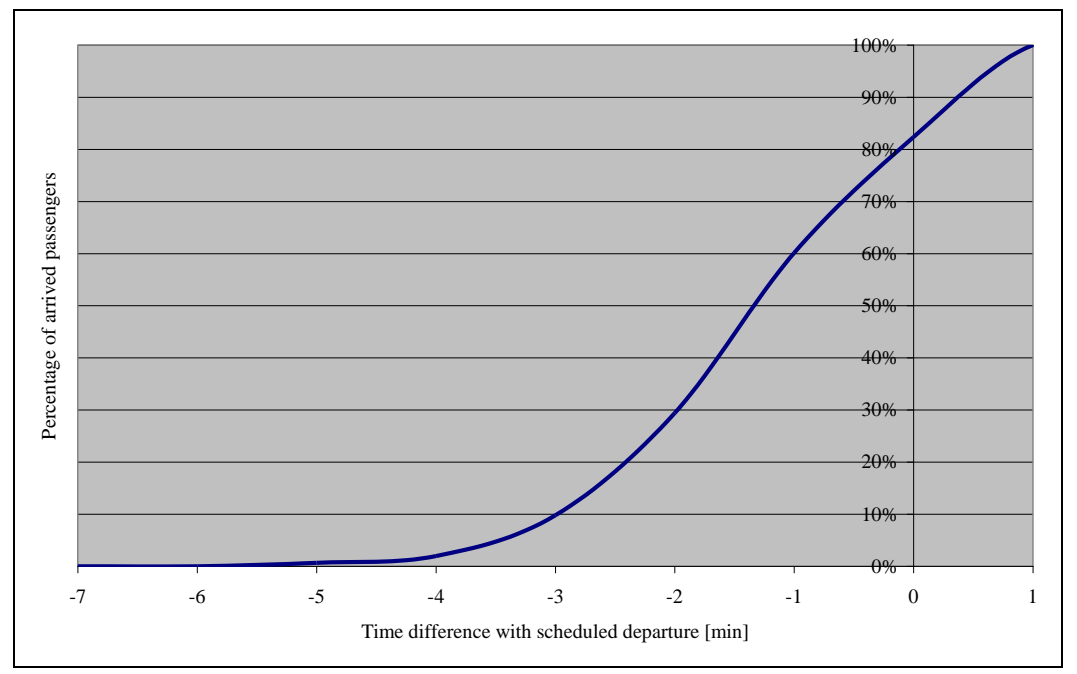

Figure 3. Percentage of Passengers Arrived as Function of Time Difference with Scheduled Departure Time (if schedule is known) [4]

The value of $\tau_{\text {late }}$ is set to 1 , because it is considered possible that passengers may speed up a little while approaching the stop in combination with drivers waiting for arriving passengers.

It is important to note that there is a difference between driving ahead of schedule and driving late. Driving ahead (i.e., departing before the scheduled departure time minus $\tau_{\text {early }}$ ) leads to a waiting time equal to the headway ( $H_{l}^{\text {sched }}$; assuming punctual departure of the successive vehicle). Especially in the case of low frequencies, this leads to a substantial increase in passenger waiting time. Arriving late creates an additional waiting time equal to the delay $\left(\tilde{d}_{l, i, j}^{\text {departure }}\right.$ ). Just as before, the additional waiting time is first calculated per stop.

$$
\begin{aligned}
& \left\{\begin{array}{l}
\tilde{T}_{l, i, j}^{\text {Add ,waiting }}=H_{l}^{\text {sched }} \\
\tilde{T}_{l, i, j}^{\text {Ad, waiting }}=0 \\
\tilde{T}_{l, i, j}^{\text {Add, waiting }}=\tilde{d}_{l, i, j}^{\text {departure }}
\end{array}\right. \\
& \text { if } \\
& \text { if } \\
& \text { if } \\
& \tilde{d}_{l, i, j}^{\text {depature }} \leq-\tau_{\text {early }} \\
& -\tau_{\text {early }}<\tilde{d}_{l, i, j}^{\text {depanture }}<\tau_{\text {late }} \\
& \tilde{d}_{l, i, j}^{\text {depature }} \geq \tau_{\text {late }} \\
& E\left(\tilde{T}_{l, j}^{\text {Add ,waiting }}\right)=\frac{\sum_{i} E\left(\tilde{T}_{l, i, j}^{\text {Add ,waiting }}\right)}{n_{l, i}}
\end{aligned}
$$




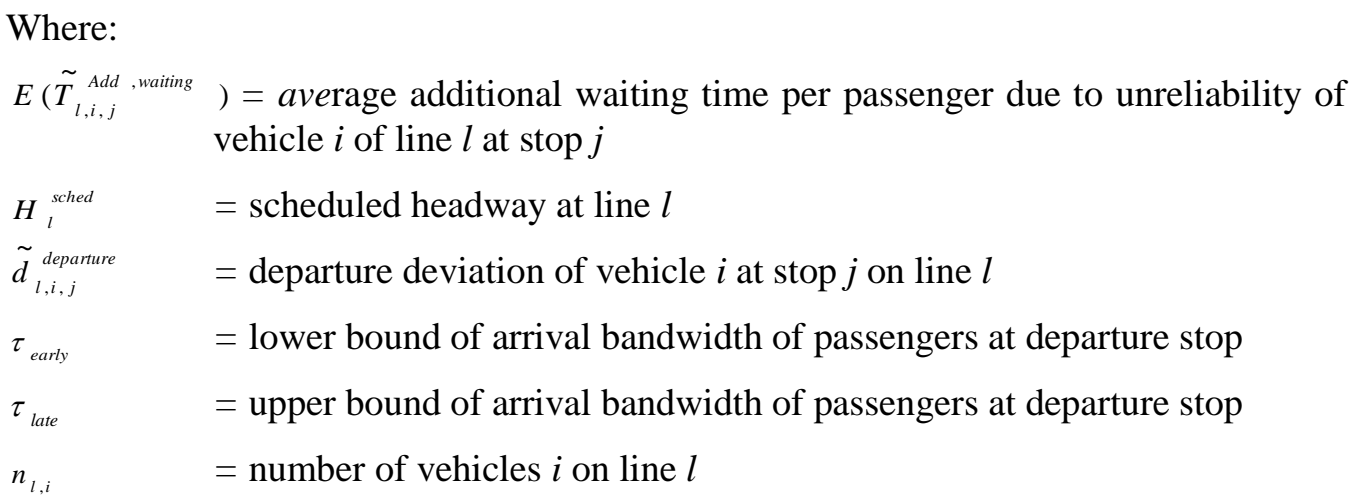

Based on the average additional travel time per passenger per stop of a line, the average additional travel time per passenger on the complete line is calculated. To do this, the proportion or percentage of boarding passengers per stop is used $\left(\alpha_{l, j}\right)$, as shown by Equation 6. Please note that using the proportion of passengers makes the indicator independent of the actual number of passengers.

$$
E\left(\tilde{T}_{l}^{\text {Add ,waiting }}\right)=\sum_{j}\left(\alpha_{l, j} * E\left(\tilde{T}_{l, j}^{\text {Add waiting }}\right)\right) \quad \text { with } \quad \sum_{j} \alpha_{l, j}=1
$$

Where: $\quad \alpha_{l, j} \quad=$ proportion of passengers of line $l$ boarding at stop $j$

The following section describes the proposed approach to obtain to translate operational data into the reliability attributes described on this section in order to be able to estimate the impacts of service reliability in a transport demand model.

\section{Unreliability Impacts in Transport Modelling}

\subsection{Three Step Approach}

The objective in this paper is to incorporate service reliability in public transport modelling in a static transport demand model by including the impacts of service reliability on passenger behaviour. Since most public transport metrics focus on vehicles and transport models deal with passengers, one of the challenges is to calculate passenger impacts. The second one is that most models do not incorporate distribution of travel times. In this research we explicitly not want to change the modelling software itself, but use existing software. The next step would be, if this research yields valuable results, to adjust the software and algorithms as well. To deal with these mentioned challenges, we developed a three-step approach. Figure 4 shows the three steps:

Step 1:Analysis of public transport schedule adherence, using AVL data;

Step 2:Calculation of passenger impacts caused by service reliability, using APC data and determination of the average additional travel time;

Step 3:Translation of passenger impacts into travel time units;

After the three steps are completed, the results can be imported into existing static transport demand models that are able to calculate the effects on public transport demand and on network performance. 


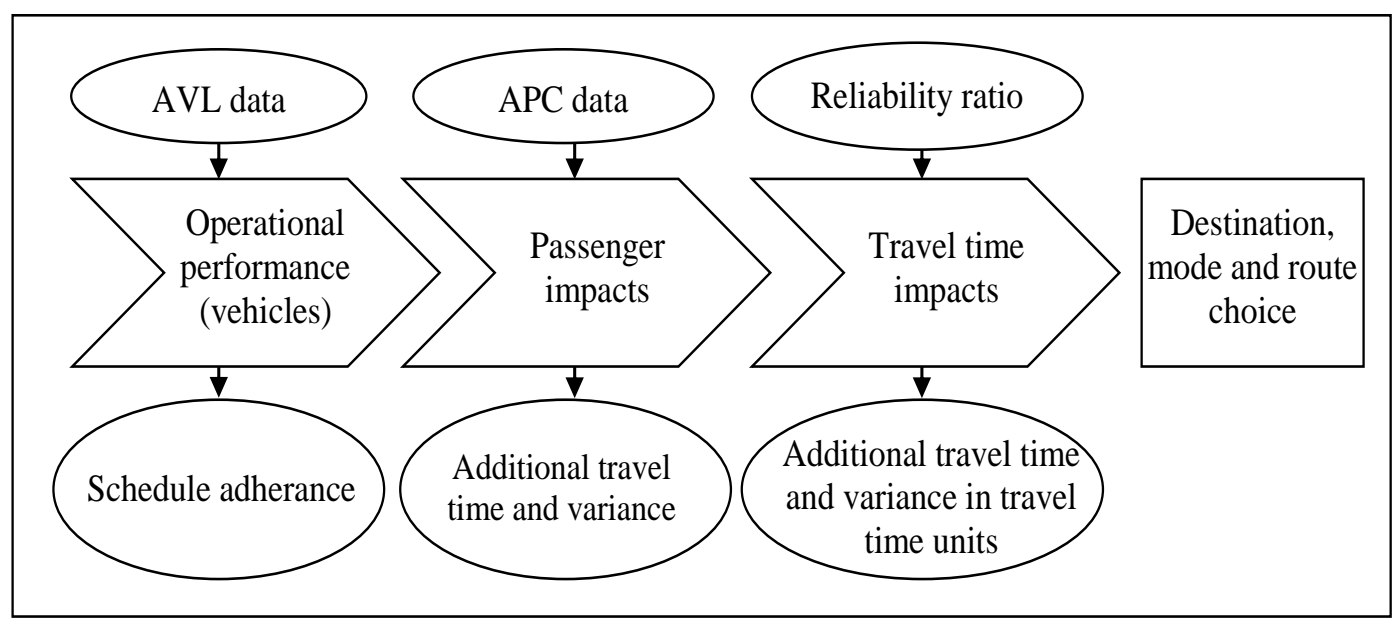

Figure 4. Three-step Approach for Incorporating Service Reliability in a Transport Model (Consisting of Vehicle Performance Analysis, Calculation of Passenger Impacts and Translation of these into Travel Time Units)

Step one provides insight into performance characteristics such as trip time, dwell time and schedule adherence by comparing the schedule to the operational performance obtained from AVL data. Early or late departures and the difference between scheduled and actual headways are determined. Public transport companies have always dealt with large amounts of data when designing timetables, scheduling vehicles and staff, collecting fares and more recently tracking vehicle locations. However, it has only recently become possible to store large amounts of historic vehicle location and fare collection data, and therefore to analyse this data. Accurate real-time vehicle location data has become available for public transport operators with the wide availability of GPS and GSM devices [31].

In Step two the travel time impacts are estimated by defining the average additional travel time, the waiting time standard deviation and the in-vehicle travel time standard deviation. Depending on the passenger arrival pattern the average additional waiting time is calculated with either Equations 2 and 3 or 4 and 5. Essential input for this step is data of passenger travel patterns, provided by APC data. Recently, many cities and regions introduced a smart card system for their public transport systems. In addition to ticket handling, being an alternative for individual regional or urban tickets, these systems also provide valuable data [32].

In step three the average additional travel time can be directly added to the base invehicle travel time (which in the transport demand model is estimated by multiplying the vehicle speed by the travelled distance) providing an average travel time ( $\breve{T}$ ). The estimation of the standard deviation of the travel time and waiting time depends on the probability distribution function of the travel time pattern. Once the standard deviations caused by the unreliability have been determined they are multiplied by a reliability ratio to transform the standard deviations into travel time units. Various values for this reliability ratio are found in literature ranging from 0.70 [18] to 1.40 [33].

\subsection{Calculation Methods}

The effects of service reliability as obtained from step three, may be added to the network in the transport demand model. For this purpose the following two strategies are proposed. 


\subsubsection{Reliability Effects at the Stop Level}

Reliability data is calculated for every section between two stops and for every stop. The reliability that is experienced within the in-vehicle travel time is included on each section. The impacts of unreliability that are experienced at the boarding stop are included at the stop in the model as a boarding additional waiting time. Consequently, when searching a route through the public transport network, the boarding penalty applies to all passengers boarding at a specific stop, while the section reliability applies to all passengers traversing this section. Therefore, on a journey on one public transport line, a passenger experiences exactly one boarding penalty and several reliability effects on all sections. In Figure 5a an example trip is shown: if a passenger boards at stop 1 and alights at stop 3 , he or she experiences the reliability at stop 1 and on two link sections.

\subsubsection{Reliability Effects at the Line Level}

A value of reliability is estimated for the public transport line as a whole, by using Equation 6 . This value is attached to the network as an unreliability factor $\left(\mathrm{F}_{l}\right)$, which is applied to the travel time for every public transport line. In Figure $5 \mathrm{~b}$ an example trip is shown: if a passenger boards at stop 1 and alights at stop 3, a reliability value proportional to the travel time between those two stops is applied.

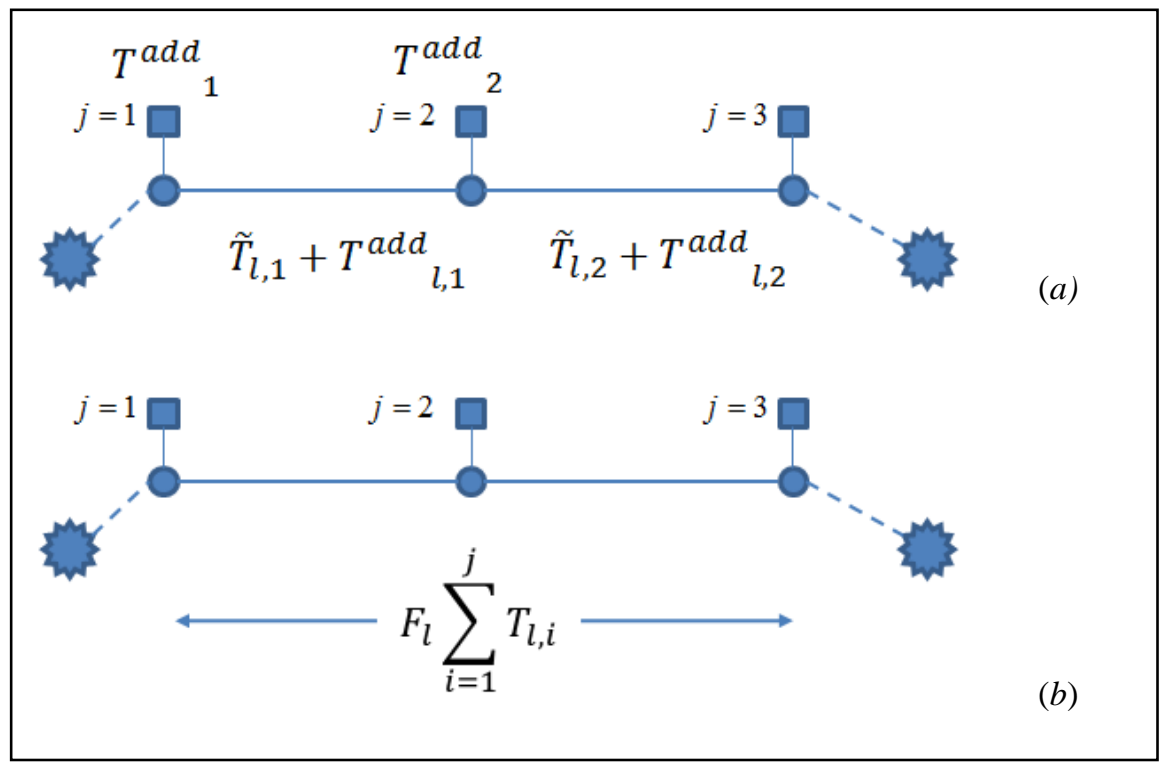

Figure 5. Reliability Effects at the Stop Level (a) and Reliability Effects at the Line Level (b)

After the service reliability data is incorporated, existing modelling techniques can be applied to calculate expected ridership. The following section describes the application of this approach to a case study in Utrecht, The Netherlands.

\section{Case study: City of Utrecht}

\subsection{New Approach Applied in VRU Model}

The first approach of incorporating service reliability in a demand model was applied in the transport model of the Utrecht region in The Netherlands. Utrecht is the fourth largest city in The Netherlands with over 300,000 inhabitants and is facing several challenges with regards to public transport. Funding is reduced, while quality is required to increase. The main issue while planning and designing public transport is predicting the 
impact of service reliability on demand and its benefits [6]. Although a transport model (VRU3.0) is available, service reliability was not accounted for until recently.

The VRU3.0 model is a multimodal transport model, containing car, bicycle and public transport (train, tram and bus). Its study area consists of the 9 municipalities cooperating in the region of Utrecht, with an influence area that covers the Netherlands and some parts of Belgium and Germany. It contains 4,400 transportation zones, approximately 50,000 links, 5,000 public transport stops and 900 public transport lines. To deal with the research question concerning service reliability the proposed three-step approach was applied as follows.

The first step is to analyze historical operations with AVL data. AVL systems are of great help to provide databases of historical performance with regards to travel time and reliability and APC data allows obtaining an exact demand pattern over distance and over time. Although such data has already been available for many operators, it is just since recently that this valuable data is also becoming available to Dutch public transport authorities, researchers and developers. Most public transport operators and authorities are involved with the initiative called Public transport Information without Borders (GOVI in Dutch), aiming at making a wide range of public transport information available from planned timetables, fares, vehicle location and punctuality [31].

GOVI was designed to facilitate data communication between vehicles and the land side enabling dynamic passenger information. An additional benefit is that all the actual and scheduled vehicle positions and times are logged in a database. Although this database was not the objective of the GOVI system, it is extremely helpful to monitor and analyze public transport performance through statistical analysis making it possible to compute travel time distributions. Figure 6 shows an example of the processed data.

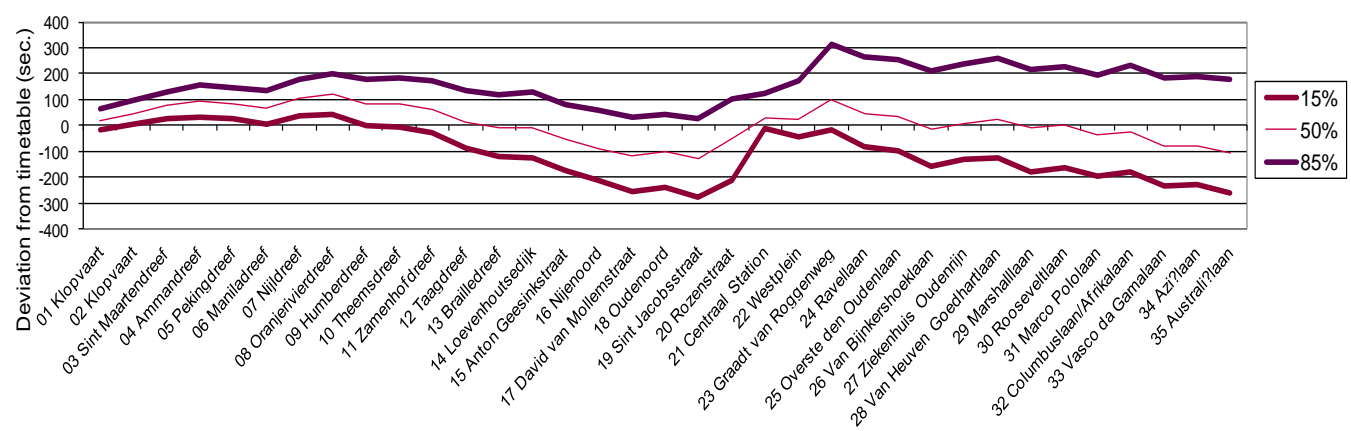

Figure 6. Example Graph, Punctuality Development, Bus Line 7 Utrecht, Evening Rush Hour

The second step is to transform the findings of step one into the average additional travel time and standard deviations. Depending on the type of public transport line and the passenger arrival pattern Equations 2 and 3 or 4 and 5 were used to calculate the average additional waiting time. The standard deviation of additional waiting times was calculated as suggested in [14 and 34] and the standard deviation of in-vehicle travel time is derived from operational data of the vehicle trip time variance assuming a normal distribution.

Dutch APC data was used to gain insights in passenger travel patterns. The Dutch smart card uses nfc-chip technology and passengers have to check in and to check out. All public transport (including train services) is accessible with this smart card. In the Netherlands, the check-in and check-out devices are either located on the platform (for trains and metros) or located inside the vehicle (for buses and trams). The most detailed information is available in the latter case, where each trip in a journey (a journey may consist of multiple trips, with a transfer in between) is tracked. An example of the raw data format, provided by the Dutch smart card transactions, is given in Table 2. Every record contains a trip, with a check-in station, check-in time, check-out station and check- 
out time. The anonymous smart card ID can be used to combine multiple trips to a journey, hence identifying the transfers. Furthermore, a public transport line number is given, so that the trip may be matched to a specific service in case multiple public transport lines run in parallel. Potentially, the vehicle number and /or run number are also given, enabling detailed analysis of distribution among individual services, for example to provide solutions for capacity problems. Furthermore, some information may be provided on smart card type / ticket type to predict trip purpose, for example an annual season ticket (usually used for commuting), a student card (usually used for education) or a special offer tickets (usually used for recreational purposes).

Table 2. A Sample of Fictitious Smart Card Data: Every Record Represents a Trip in a Public Transport Vehicle. For Simplicity, all Data in this Example is for a Specific Date

\begin{tabular}{|l|l|l|l|l|l|l|l|}
\hline Chip ID & $\begin{array}{l}\text { Check in } \\
\text { stop }\end{array}$ & $\begin{array}{l}\text { Check } \\
\text { out stop }\end{array}$ & $\begin{array}{l}\text { Check in } \\
\text { time }\end{array}$ & $\begin{array}{l}\text { Check } \\
\text { out time }\end{array}$ & $\begin{array}{l}\text { Line } \\
\text { number }\end{array}$ & $\begin{array}{l}\text { (vehicle } \\
\text { number) }\end{array}$ & $\begin{array}{l}\text { (ticket } \\
\text { type) }\end{array}$ \\
\hline 1 & 35 & 488 & $10: 27$ & $10: 52$ & 9 &.. & $\begin{array}{l}\text { Regular } \\
\text { single }\end{array}$ \\
\hline 2 & 23 & 86 & $8: 01$ & $8: 09$ & 1 &.. & Student \\
\hline 2 & 86 & 90 & $8: 17$ & $8: 55$ & 3 &.. & Student \\
\hline 3 & 73 & 94 & $7: 20$ & $7: 53$ & 4 &.. & $\begin{array}{l}\text { Annual } \\
\text { ticket }\end{array}$ \\
\hline 3 & 94 & 73 & $16: 55$ & $17: 27$ & 4 &.. & $\begin{array}{l}\text { Annual } \\
\text { ticket }\end{array}$ \\
\hline
\end{tabular}

In order to estimate the reliability ratio (step three) for this study the value of time (VOT) and the value of reliability (VOR) were used. The values are taken from [35] which were corrected by inflation to year 2011, as shown in Table 3. This survey states that service reliability is valued $40 \%$ higher than travel time. Using these insights, the values of standard deviation where multiplied by a 1.4 factor to be added in travel time units to the generalized cost functions of the demand model. The waiting time portion of the travel time includes now the reliability effects consisting of: scheduled waiting time, average additional waiting time and additional waiting caused by variance.

Table 3. Value of Time and Value of Reliability in 2011

\begin{tabular}{|l|l|l|}
\hline Travel purpose & $\begin{array}{l}\text { Value } \\
\text { of time } \\
(\boldsymbol{\epsilon} / \text { hour })\end{array}$ & $\begin{array}{l}\text { Value } \\
\text { of reliability } \\
(\boldsymbol{\epsilon} / \text { hour })\end{array}$ \\
\hline Commuter & 10.00 & 14.00 \\
\hline Business & 17.44 & 24.42 \\
\hline Other & 6.33 & 8.86 \\
\hline
\end{tabular}

Similarly, in-vehicle travel times were calculated, consisting of scheduled in-vehicle time and additional in-vehicle travel time caused by variance. After all the calculation of new waiting and in-vehicle times for all stops and links were performed both strategies were tested by incorporating these values in the transport model in the generalized cost matrix for all origin and destination pairs. Finally regular calculations on expected public transport demand were performed by the model.

This approach is one step towards a full incorporation of service reliability in public transport modelling. The next section presents the results from both approaches and demonstrates the success of this method. 


\subsection{Results}

To illustrate the added value of this approach, the results of the synthetic model (the model results before calibration) with and without taking service reliability impacts into account are compared. These results indicate that the explanatory power of the model has changed and the method was beneficial.

For an area in the southern part of the Utrecht area, mainly consisting of the town of Nieuwegein, we compared the synthetic model results with 24 count values, using both strategies to incorporate reliability. Data was available for the buses and tram lines operated by the region of Utrecht. Below, the main findings of applying the three-step approach are presented. Table 4 summarizes them.

\section{Table 4. Results of Applied Approach (including Service Reliability) in Utrecht Model Compared to Case without Service Reliability}

\begin{tabular}{|l|l|l|}
\hline Impacts & $\begin{array}{l}\text { Strategy 1 } \\
\text { Reliability effects at the stop } \\
\text { level }\end{array}$ & $\begin{array}{l}\text { Strategy 2 } \\
\text { Reliability effects at the line } \\
\text { level }\end{array}$ \\
\hline $\begin{array}{l}\text { Public transport counts } \\
\text { Improved fit } \\
\text { Worse fit }\end{array}$ & $\begin{array}{l}15 \\
9\end{array}$ & 13 \\
\hline $\begin{array}{l}\text { Absolute difference observed values } \\
\text { and model results }\end{array}$ & $18 \%$ improvement & No improvement \\
\hline Other impacts & $\begin{array}{l}\text { Possibility of calculating } \\
\text { impacts of improved service } \\
\text { reliability }\end{array}$ & $\begin{array}{l}\text { Possibility of calculating } \\
\text { impacts of improved service } \\
\text { reliability }\end{array}$ \\
\hline Other impacts & $\begin{array}{l}\text { Data provision for cost benefit } \\
\text { analyses (with regard to } \\
\text { service reliability impacts) }\end{array}$ & $\begin{array}{l}\text { Data provision for cost benefit } \\
\text { analyses (with regard to } \\
\text { service reliability impacts) }\end{array}$ \\
\hline
\end{tabular}

\section{Strategy 1: Reliability effects at the stop level}

From the 24 public transport count values, 15 synthetic model results show an improved fit and 9 results show a worse fit. In total, the absolute difference between observed values and the synthetic model results decreased by $18 \%$ (from 3,300 to 2,700 on a total amount of 9,300). This indicates a substantial improvement of the prediction process.

\section{Strategy 2: Reliability effects at the line level}

From the 24 count values, 13 synthetic model results show an improved fit and 11 results show a worse fit. In total the absolute difference between observed and synthetic model results is at a similar level of approximately 3,300. This indicates only a limited improvement of the prediction process.

Both strategies show more or less improvements concerning the fit of the synthetic model data to count data. Further, the assignment showed that a shift took place from less reliable bus lines to more reliable tram lines, which is in line with the expectations. In Figure 7, this is illustrated. The tram line "attracts "more passengers in case of incorporated service reliability (in green) and passengers "leave" the bus line (in red) . 


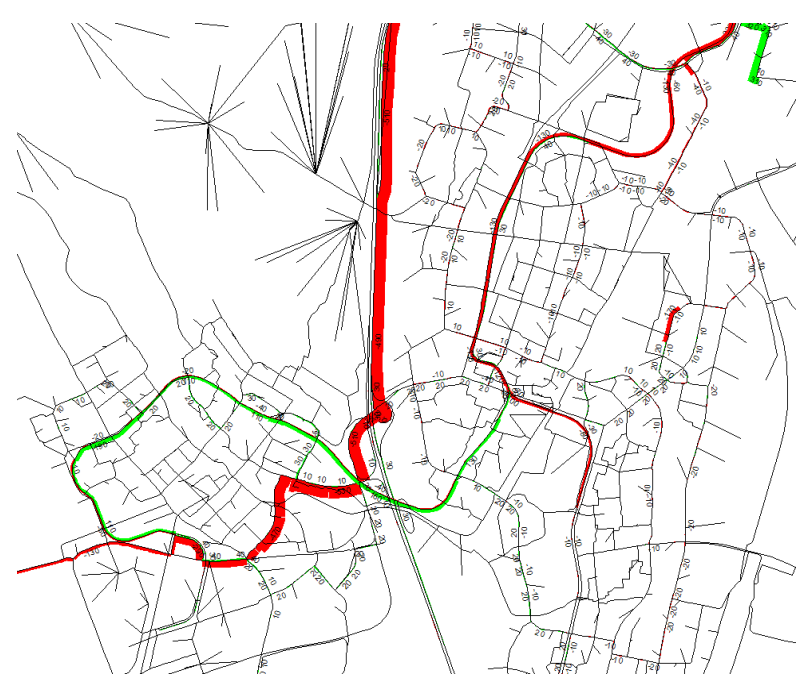

\section{Figure 7. Differences in Link Loads with and without Incorporating Service Reliability (Green Indicates more Passengers in Case of Incorporating Reliability, Red Means Less Passengers)}

In addition to improved prediction quality, this approach also yields other valuable opportunities. Since we succeeded in incorporating service reliability impacts in the transport model, we are now also able to calculate the impacts of expected changes in the service reliability on public transport demand. This is of great help to find optimal choices in both network and timetable design. The third benefit of our approach is that the result of the service reliability impacts on passengers are directly available as input for cost benefit analysis which was hardly possible until now [6].

From the literature review, the approach of including both travel time extension and standard deviation in the transport demand model seems the most appropriate choice in static modelling. However, this will be subject to future research.

Research is still needed on the value of the reliability ratio. In this research an estimate based on the ration between the value of time and the value of reliability has been used. However, other researchers found that the value of this ratio largely varies, depending on the purpose of the trip and / or the socio economical characteristics of the passenger. More insights would be valuable.

Since this research yielded valuable research, we recommend continuing to the next step, which is adjusting the software. In general, this means to adjust the utility function by adding an additional variable for distribution of travel time.

Ultimately it is recommended to apply the methodology presented in this article to more public transport lines to determine if in general a stop or line approach, or maybe even a mode approach, yields better results.

\section{Conclusions}

This paper dealt with service reliability in public transport (modelling). Service reliability is considered very important, both from a passenger and an operator perspective. Surprisingly, this quality aspect is not explicitly considered in transport demand models, which limits the prediction accuracy of the models. In addition, it is not possible to calculate the impacts of expected changes in level of service reliability. Service reliability time impacts are not available as model output, but necessary for cost benefit analyses.

In the long term, improvements of transport models will be necessary, but to deal with service reliability and ridership on the short term, we developed a three-step approach to incorporate service reliability when calculating expected ridership. We applied this 
approach with success in a case study in the city of Utrecht in The Netherlands. The threestep approach consists of analyzing operational performance, calculating passenger impacts and finally transforming these into travel time impacts. Transport models are able to deal with these and therefore all their standard functionalities can be used. Adding service reliability as a variable of transit systems improved the results of the demand model: the absolute difference between the observed and the estimated demand decreased by $18 \%$. In addition, the proposed approach allows measuring the effects of expected changes in level of service reliability on traveller behaviour.

The three-step approach proved to be a promising approach for the short term. We will continue our research to deal with service reliability in a more detailed way. To achieve that, utility functions could be adjusted in a way that service reliability will explicitly taken into account in the choice processes, instead of the presented approach where service reliability impacts are translated into travel time units.

\section{Acknowledgements}

This research is performed in cooperation with BRU, the transit authority in the region Utrecht, the Netherlands, Delft University of Technology, Department of Transport \& Planning, Goudappel Coffeng and DAT.Mobility.

\section{References}

[1] Outwater, M. L. and B. Charlton, "The San Francisco Model in Practice. Validation, Testing and Application", Proceedings of the $42^{\text {nd }}$ conference on Innovations in Travel Demand Modeling. Transportation Research Board of the National Academies, (2006), Austin, Texas, pp. 24-29.

[2] Petersen, E. and P. Vovsha, "Directions for Coordinated Improvement of Travel Surveys and Models", Proceedings of the $42^{\text {nd }}$ conference on Innovations in Travel Demand Modeling. Transportation Research Board of the National Academies, (2006), Austin, Texas, pp. 85-88.

[3] Hollander, Y., "Direct versus indirect models for the effects of unreliability", Transportation Research, Part A: Policy and Practice, Vol. 40, No. 9, (2006), pp. 699-711.

[4] Oort, N. van., "Service Reliability and Urban Public Transport Design", TRAIL. PhD Thesis Series T2011/2, Delft, The Netherlands, (2011).

[5] Cham, L.C., N.H.M. Wilson (2006), Understanding bus service reliability, A practical framework using AVL/APC data, Washington DC.

[6] Oort, N. van., "Quantifying benefits of enhanced service reliability in public transport", presented at the 12th Conference on Advanced Systems for Public Transport (CASPT), (2012), Santiago, Chili.

[7] Oort, N. van, J. W. Boterman and R. van Nes, "The impact of scheduling on service reliability: trip-time determination and holding points in long-headway services", Public Transport, 4, 1, (2012).

[8] Furth, P. G. and T. H. J.Muller, "Service Reliability and Hidden Waiting Time: Insights from Automated Vehicle Location Data", Transportation Research Record: Journal of the Transportation Research Board, 1995, (2006).

[9] Hickman, M., "Evaluating the Benefits of Bus Automatic Vehicle Location (AVL) Systems", Chapter 5 in D. Levinson and D. Gillen (eds.), Assessing the Benefits and Costs of Intelligent Transportation Systems, Kluwer, Boston, (2004).

[10] Pelletier, M., M. Trepanier and C.Morency, "Smart card data use in public transit: A literature review", Transportation Research Part C: Emerging Technologies, 19, 4, (2011).

[11] Wilson, N.H.M., A. Macchi, R.E. Fellows, A.A. Deckoff, "Improving service on the MBTA green line through better operations control”, Transportation Research Record, No. 1361, (1992), pp. 296-304.

[12] Van Oort, N., N.H.M. Wilson, R. van Nes, "Reliability improvement in short headway transit services: schedule-based and headway-based holding strategies", Transportation Research Record, No. 2143, (2010), pp. 67-76.

[13] Eberlein, X. J., N.H.M. Wilson, D. Bernstein, "The holding problem with Real-Time Information available", Transportation Science, Vol. 35, No. 1, (2001) pp. 1-18

[14] Bates, J., J. Polak, P.Jones and A.Cook, "The valuation of reliability for personal travel", Transportation Research Part E: Logistics and Transportation, 37, 2, (2001).

[15] Rietveld,P., F. R. Bruinsma and D. J. van Vuuren, "Coping with unreliability in public transport chains: A case study for Netherlands", Transportation Research A: Policy and Practice, 35, 6, (2001).

[16] Small, Kenneth A., "Scheduling of consumer activities: work trips". American Economic Review, (1982), pp. 467-479.

[17] Jackson, W B, J. V. Jucker. "An Empirical Study of Travel Time Variability and Travel Choice Behavior". Transportation Science, 16, (1982), pp. 460-475. 
[18] Noland, R. and J. Polak, "Travel time variability: a review of theoretical and empirical issues", Transport Reviews, 22, 1, (2002).

[19] Significance, VU University Amsterdam, \& John Bates Services. "Values of time and reliability in passenger and freight transport in The Netherlands". Report for the Ministry of Infrastructure. Technical report.(2013).

[20] Paulley, N., R. Balcombe, R. Mackett, H. Titheridge, J. M. Preston, M. R. Wardman, J. D. Shires and P. White, "The demand for public transport: The effects of fares, quality of service, income and car ownership", Transport Policy, 13, 4, (2006).

[21] Brands, T., E. de Romph and T. Veitch, "Modelling public transport route choice with multiple access and egress modes", Proceedings of the 41st European Transport Conference, (2013), Frankfurt, Germany.

[22] Lee, A. N. van Oort, R. van Nes, "Service reliability in a network context", Transportation Research Record, No. 2417, (2014), pp. 18-26.

[23] Welding, P.I., "The instability of a close interval service", Operational Research Quarterly, 8, 3, (1957).

[24] Noland, R., K.A. Small, "Travel time uncertainty, departure time and the cost of the morning commute", Transportation Research Record: Journal of the Transportation Research Board, 1493, (1995).

[25] Oort, N. van and R. van Nes, "Regularity analysis for optimizing urban transit network design", Public transport, 1, 2, (2009).

[26] Hensher, D. A., J. M.Rose and A. Collins, "Identifying Commuter Preferences for Existing Modes and a Proposed Metro in Sydney, Australia", Public Transport: Planning and Operations, 3, 2, (2011).

[27] Kanacilo, E. M. and N. van Oort, "Using a rail simulation library to assess impacts of transit network planning on operational quality", J. Allen, E. Arias, C.A. Brebbia, C.J. Goodman, A.F. Rumsey, G. Sciutto and N. Tomii (Eds.), Computers in railways XI, Southampton, UK. WITpress, (2008), pp. 35-44.

[28] Van Oort, N., "Incorporating service reliability in public transport design and performance requirements: International survey results and recommendations", Research in Transportation Economics, Volume 48, (2014), Pages 92-100.

[29] Osuna, E. E. and G. F. Newell. "Control strategies for an idealized public transport system", Transportation Science, 6, 1, (1972).

[30] Heap, R. C. and T. H. Thomas, "The modelling of platooning tendencies in public transport.", Traffic Engineering and Control, 8, 9, (1976) ,pp.360-362.

[31] Oort, N. van, D. Sparing, T. Brands and R. Goverde, "Optimizing Public Transport Planning and Operations Using Automatic Vehicle Location Data: The Dutch Example", Proceedings of the 3rd International Conference on Models and Technology for ITS, (2013), 2-4 December, Dresden, Germany.

[32] Bagchi, M, P. White. The Potential of Public Transport Smart Card Data. Transport Policy, Vol. 12, No. 5, (2005), pp 464-474.

[33] SHRP 2 Reliabilitty Project L05: "Incorporating Reliability Performance Measures into the Transportation Planning Programming Processes", Transportation Research Board of the National Academies, Strategic Highway Research Program, Washington, D.C., (2013), pp. 38-40.

[34] Turnquist, M.A. and L.A. Bowman, "The effects of network structure on reliability of transit service", Transportation Research Part B: Methodological, Vol. 14, No. 1-2 (1980), pp.79-86.

[35] RAND Europe and AVV: The value of reliability in transport: Provisional values for The Netherlands based on expert opinion, Report TR-240, Rand Europe, Leiden, The Netherlands, (2005).

\section{Authors}

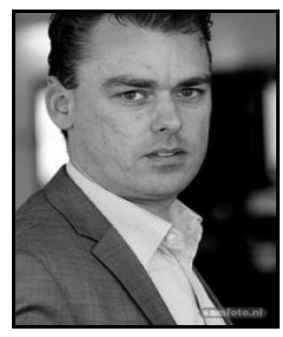

Dr. N. (Niels) van Oort M.Sc., Niels van Oort works as an assistant professor Public Transport at Delft University of Technology and via his job as a public transport consultant at Goudappel Coffeng he is involved in several public transport projects. His main fields of expertise are public transport planning, dealing with the passenger perspective, service reliability and Big Data. In addition to teaching, Niels often presents his work at conferences and he frequently publishes articles in (international) journals.

Niels studied traffic and transport at Delft University of Technology and finished his Master on Public Transport in 2003. He started to work as a researcher at HTM, the public transport company of The Hague. During this job, he started a PhD on service reliability in public transport. He performed his research part time at Delft University of Technology and in 2009 he joined the public transport research group of Professor Wilson at MIT. In 2010 he changed jobs and is now working as a public transport consultant at Goudappel Coffeng mobility consultants. He finished his $\mathrm{PhD}$ in 2011 and 
started to work at Delft university of Technology in 2012 as an assistant professor focussing on research of passenger reliability in the total trip chain. He is involved in several studies concerning network and timetable optimization, thereby applying his research into practice.

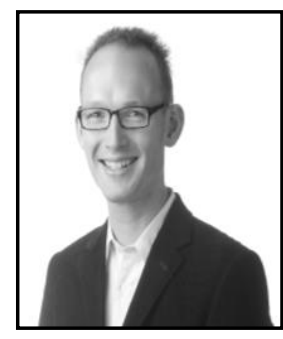

T. (Ties) Brands M.Sc., is a $\mathrm{PhD}$ candidate at the Centre for Transport studies at the University of Twente (The Netherlands). He received his BSc degree (Civil Engineering) in 2004 and his two MSc degrees (Civil Engineering and Applied Mathematics) in 2008. His MSc thesis was on optimization of dynamic road pricing and was conducted at the Dutch consultancy company Goudappel Coffeng. After graduation, Ties started working at Goudappel Coffeng as a public transport consultant, with specialization in public transport modeling and data analysis. Parallel to his work as a consultant, he started a PhD project at the Centre for Transport Studies on multiobjective optimization of multimodal passenger transportation networks.

Prof. dr. ir. (Erik) de Romph, is professor in Strategic

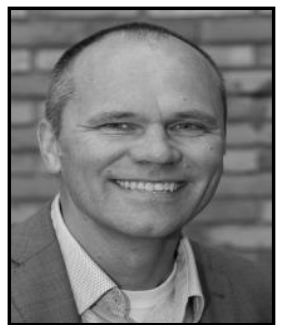

Transport Models at Delft University of Technology and Scientific Director at DAT.mobility.

Erik has a master in Mathematics and Computer Science (1987) and did a PhD in Transport Modelling (1994) at Delft University of Technology. Erik worked at Goudappel Coffeng from 1995 up to 2003 and involved in various projects related to transport modelling and software development. In 2003 a separate company was formed around the product OmniTRANS. From 2007 to 2013 he was the managing director of this company called Omnitrans International. In 2014 this company merged into DAT.Mobility where Erik is Scientific director and responsible for innovation and product development roadmaps. In 2013 Erik accepted a part-time position as professor in Transport Modelling at Delft University of Technology. Erik is responsible for the development of OmniTRANS and involved in various research projects around transport modelling. 
International Journal of Transportation

Vol.3, No.1 (2015) 